\title{
A Light and Electron Microscopic Study of Lamellated Nerve Endings Found in the Rat Cheek Mucosa*
}

\author{
Ii-Sei WATANABE ${ }^{1}$ and Eichi YAMADA ${ }^{2}$ \\ Department of Anatomy, ${ }^{1}$ Institute of Biomedical Science, University São Paulo, São Paulo, Brazil and \\ Departmen of Anatomy (Prof. E. YAMADA), University of Fukuoka School of Medicine, Fukuoka, Japan
}

Received June 4, 1985

Summary. Lamellated nerve endings in the cheek mucosa of fifteen adult Sprague-Dawly rats were studied with light and electron microscopes.

Serial sections revealed that the terminal axon of the lamellated nerve endings is in the central portion, and that the inner core is made up of two stacks of lamellae. These are characterized by many corpuscles located within a single papilla, which shows structural specializations at several levels.

Electron microscopy showed that the corpuscles are circular in shape and that the lamellar sheets possess a rich rough endoplasmic reticulum, mitochondria and numerous glycogen-like granules. Numerous bundles of collagen fibers and an amorphous substance are located in the interlamellar spaces. The axon terminal is characterized by the presence of neurofilaments, neurotubules and mitochondria.

The capsule consists of several laminae formed by cytoplasmic extensions of perineural cells presenting many caveolae, mitochondria, rough endoplasmic reticulum profiles and microfilaments.

The encapsulated nerve endings in rat oral mucosa have been described only by Martinez and Pekarthy (1974). Watanabe and Yamada (1979) and Watanabe and YAMADA (1983) have similary described encapsulated nerve endings in the rat gingiva, and Berkovitz et al. (1983) have found like corpuscles in the periodontal ligament.

NiKAI et al. (1971) described the fine structure of Merkel cells in the rat gingiva; Hashimoto (1972) did the same in the human oral mucosa; Saxod (1978) in the palate mucosa of chicken; Tachibana (1978) in the labial ridge epidermis of the anuram tadpole; Garant et al. (1980) in the palate mucosa of the squirrel monkey and TACHIBANA et al. (1982) in the labial mucous epithelium of adult rabbits.

The structure of some other types of lamellated nerve endings, such as Pacinian corpuscles, has been reported by Pease and Quilliam (1957), Chouchkov (1971) and SPENCER and Schaumburg (1973).

Since the ultrastructure of lamellated nerve endings in the subepithelial area of the oral mucosa is very complex, this study was undertaken for the purpose of its clarification. In this paper, we shall describe the detailed structure as revealed by electron microscopic observation of the sensory corpuscles in the rat cheek mucosa with special attention given to the relationships between the axon terminals and lamellar cells.

*This research was supported by Grants JSPS/EP/77221 and JSPS/EP/78191 from the "Japan Society for the Promotion of Science." 


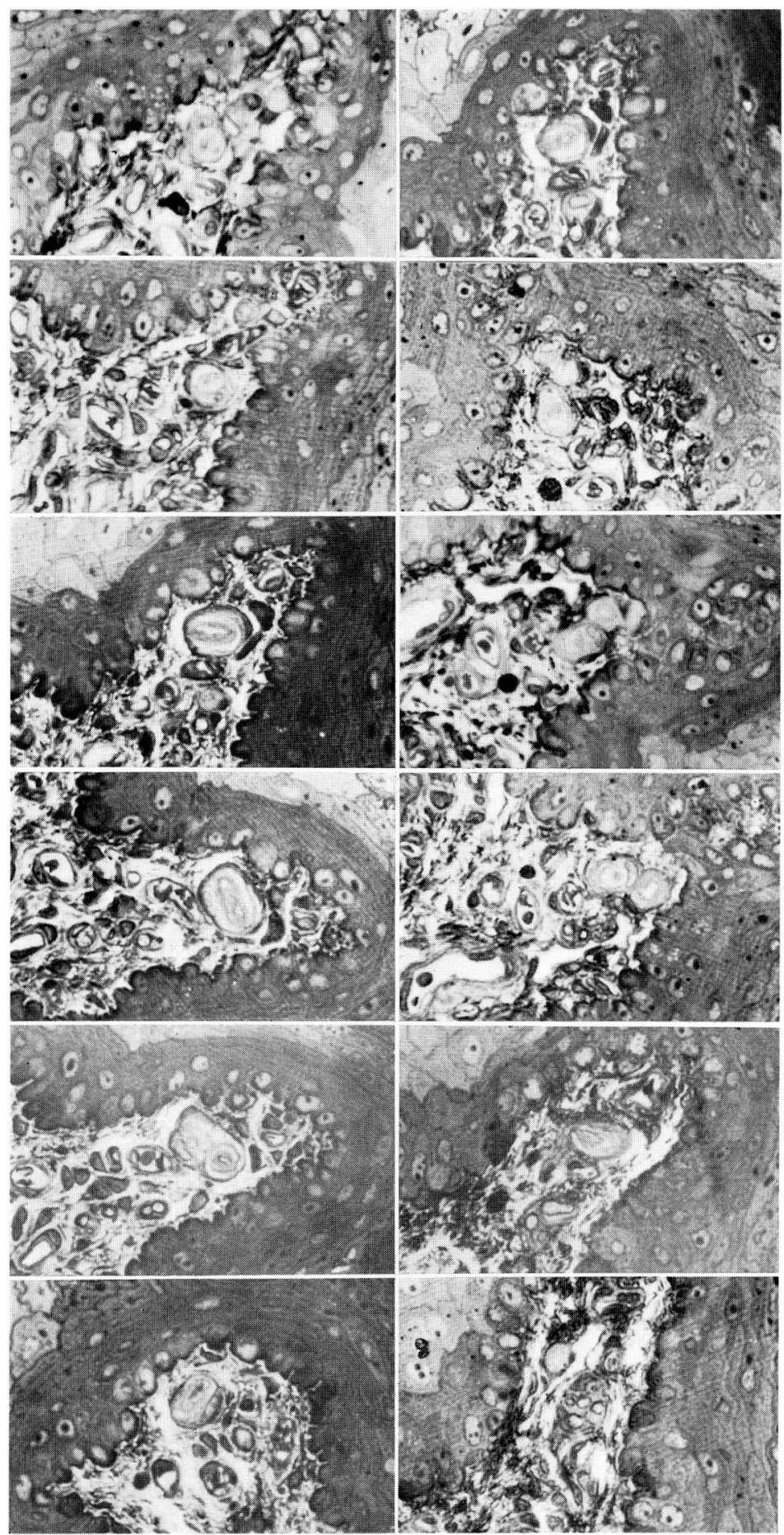

Fig. 1. Legend on the opposite page. 

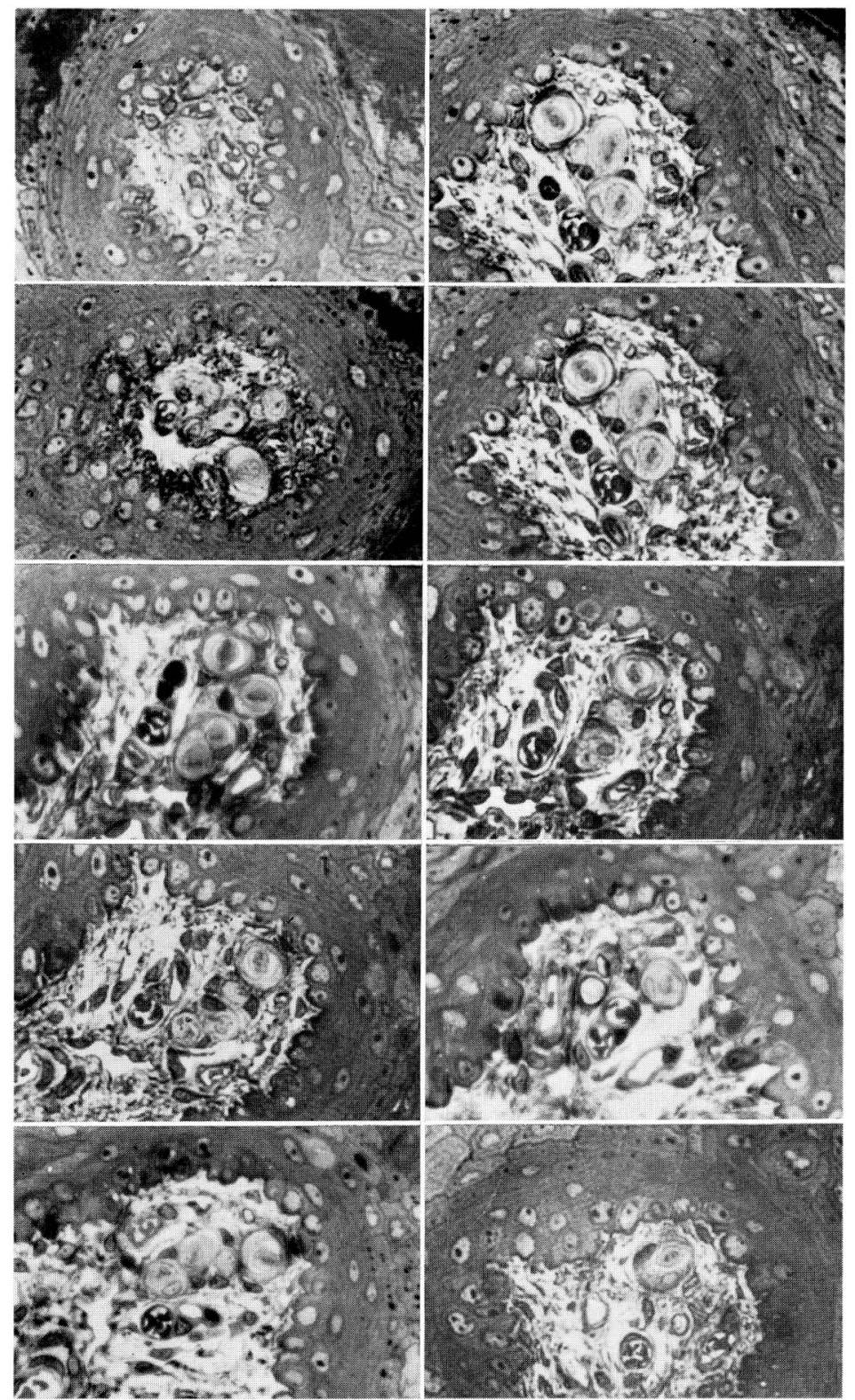

Fig. 2. Photomicrographs of incomplete serial sections showing the presence of multiple corpuscles located in the same papilla. Eponembedded semi-thin sections stained with toluidine blue. One to four lamellated corpuscles are evident, as well as the nuclei of lamellar cells and the terminal axon. $\quad \times 320$

Fig. 1. Photomicrographs of serial sections of a papilla in the cheek mucosa showing lamellated corpuscles. Epon-embedded semithin sections are stained with toluidine blue. One or two corpuscles are seen. Nuclei of lamellar cells are evident. The terminal axon is seen in the central portion. $\times 320$ 


\section{MATERIAL AND METHODS}

Fifteen Sprague-Dawly rats were anesthetized using thionembutal and perfused in the left ventricle of the heart with a modified Karnovsky's fixative containing $2.5 \%$ glutaraldehyde and $2 \%$ paraformaldehyde in a $0.1 \mathrm{M}$ phosphate buffer ( $\mathrm{pH} 7.4$ ). The cheek mucosa was excised and immersed in the above fixative for $3 \mathrm{hrs}$ at room temperature. The material was cut into small pieces in the same solution. The tissues were then washed in a $0.1 \mathrm{M}$ phosphate buffer for about $10 \mathrm{~min}$, and postfixed in $1 \%$ phosphatebuffered osmium tetroxide ( $\mathrm{pH} \mathrm{7.4)}$ for $2 \mathrm{hrs}$ at $4^{\circ} \mathrm{C}$. They were dehydrated through increasing concentrations of ethanol after "en bloc" staining in 5\% aqueous uranyl acetate solution and then embedded in Spurr's resin.

After embedding, the sections were cut on an LKB ultramicrotome using glass knives.

Semi-thin serial transverse sections approximately $2 \mu \mathrm{m}$ thick were mounted on glass slides and stained with toluidine blue for light microscopic study. Thin sections of selected areas were cut and stained with uranyl acetate and lead citrate and then examined in a Hitachi-12 A electron microscope.

\section{RESULTS}

\section{Light microscopy}

A lamellated corpuscle in the cheek mucosa was sectioned serially as shown in Figure 1. The proximal parts were circular in outline, but medial portions were elliptical or elongated. The sections also revealed that the inner core was made up of two stacks of lamellae. The nuclei of the lamellar cells were evident in these sections.

The terminal axon was in the central portion and extended longitudinally from the proximal to the distal poles (Fig. 3). The structure of the axons changed as they traversed the several levels represented in the sections (Fig. 1). The configuration of the corpuscle also changed, and the distal portion of this corpuscle was covered by laminae of lamellar cells. There also was a layer of collagen fibers surrounding the corpuscle.

A second series was incomplete serial sections of lamellated corpuscles, shown in Figure 2. These micrographs show the presence of many corpuscles located within one dermal papilla. In the proximal part (Fig. 2) one can see a lamellar cell with its nucleus. Figure 2 clearly demonstrates the existence of four separated corpuscles. These corpuscles are well defined in Figure 2. They vary in morphology at each level of sectioning. At level 15 the axons are located centrally and the lamellar cells are localized bilaterally.

Subsequent figures show the presence of single axons and modifications of morphology at various levels. The nuclei of the lamellar cells are evident at all levels.

\section{Electron microscopy}

The proximal part of a lamellated corpuscle in the cheek mucosa was circular in cross sections. The myelinated nerve fiber losts ist myelin sheath before entering the corpuscle (Fig. 3).

At this level, the cytoplasm of the large lamellar cell was well developed, displaying rough endoplasmic reticulum, mitochondria and numerous glycogen-like granules. 


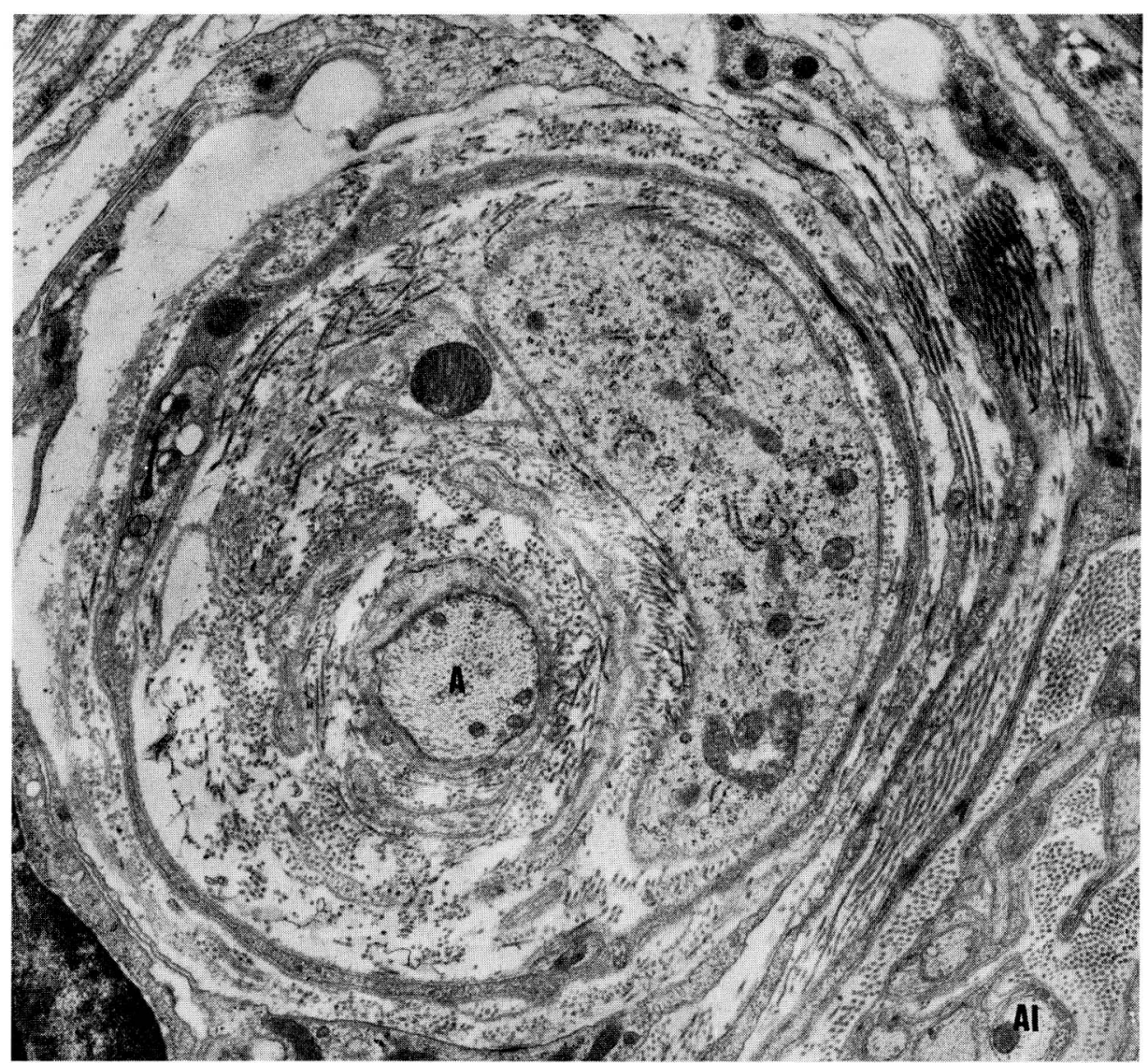

Fig. 3. A terminal axon $(A)$ and several unmyelinated axons (A1) are shown. Flat capsular cells contain dense cytoplasm. Collagen fibers accompany them. $\times 17,500$

The inner investment presented small cytoplasmic laminae of lamellar cells. Numerous bundles of collagen fibers ran in several directions through the wide interlamellar spaces. The axon showed neurofilaments, neurotubules, and mitochondria (Fig. 3). The capsule was formed by several layers of cytoplasmic extensions of perineurial cells.

The inner core showed numerous cytoplasmic extensions of lamellar cells, which were irregular in shape (Fig. 4). These extensions were variable in thickness and contained rough endoplasmic reticulum, mitochodria and microfilaments. The more peripheral cytoplasmic extensions were also rich in organelles.

The axon terminals contained many mitocondria, neurofilaments, neurotubules and clear vesicles (Fig. 4). The vesicles were most abundant in the peripheral part of the axon. A few dense cored vesicles were also present. Desmosome-type junctions connected axon and adjacent lamellae (Fig. 4). Between adjacent lamellae there were also desmosome-type junctions (Fig. 4). Along the surfaces of the lamellar cells were many caveolae (Fig. 4). The interlamellar space was generally narrow and contained many collagen fibers and an amorphous ground substance.

The capsules of these corpuscles comprised several laminae formed by cytoplasmic extensions of perineurial cells. These extensions had many caveolae, mitochondria, 


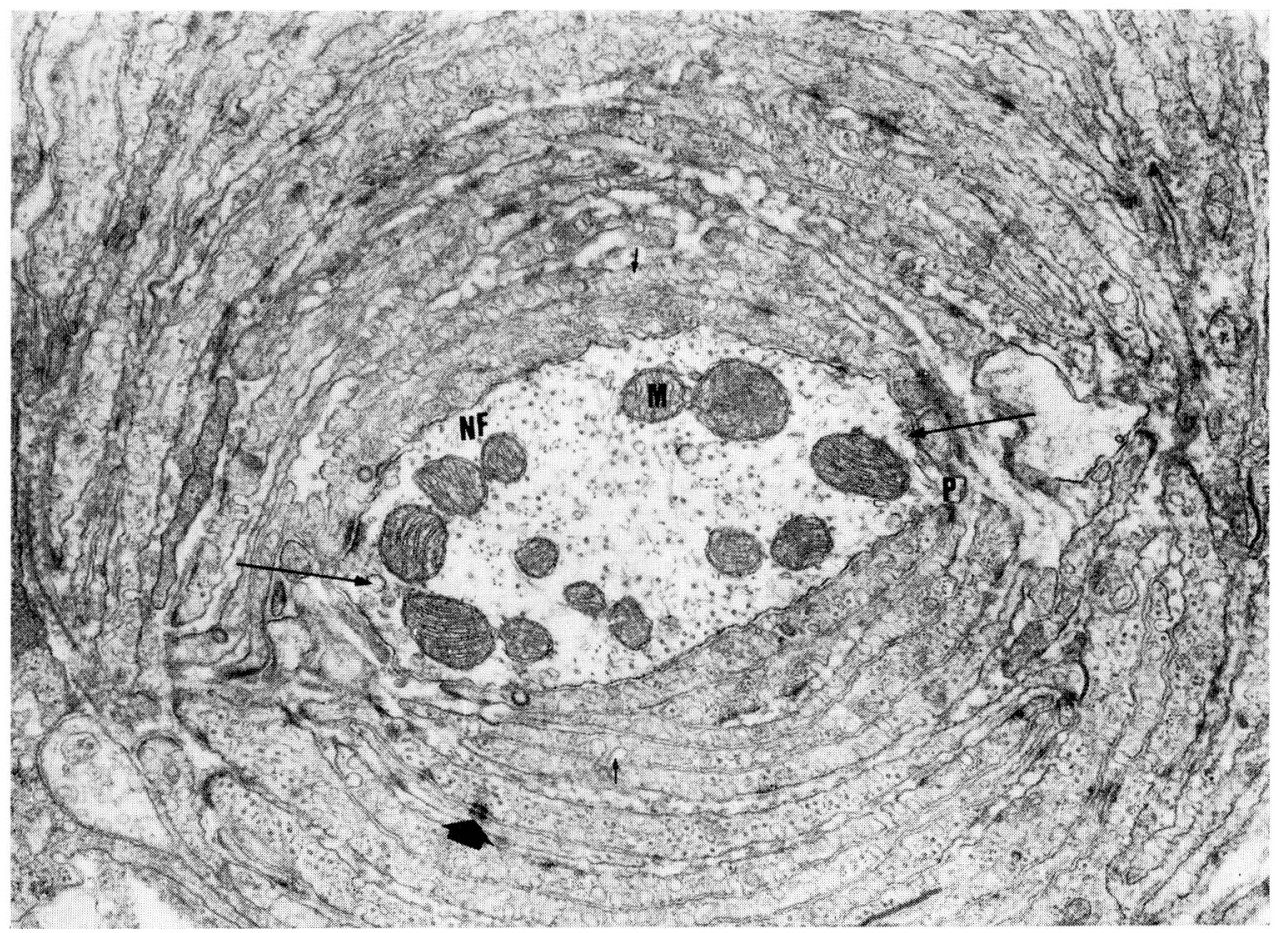

Fig. 4. Higher magnification of a terminal axon showing numerous mitochondria ( $M$ ), neurofilaments $(N F)$, vesicles (arrows) and axoplasmic extensions $(P)$. Note the desmosome-type junctions (large arrows) between neighboring laminae, and the caveolae (small arrows). $\times 31,000$

profiles of rough endoplasmic reticulum and microfilaments (Fig. 5). Collagen fibers and an amorphous ground substance were noted between the laminae.

\section{DISCUSSION}

Our results show that the size and form of the corpuscles presented in this study are almost the same as those found in the rat gingiva (WATANABE and YAMADA, 1979, 1983). Since similar features are present in both regions, we assume that they may act in the same manner in response to stimuli to either the mucosa of the cheek or gingiva.

The serial sections observed by light microscopy revealed that several corpuscles occupied the same papilla. Some papillae contained many corpuscles. Single corpuscles could also be noted in many regions as was described by Munger and Pubols (1972). The corpuscles oriented in different directions may act to transmit stimuli from a corresponding direction. However, the functions of many of the corpuscles are quite difficult to interpret because physiological data are lacking. Nevertheless, some morphological characteristics have been described by Martinez and Pekarthy (1974) and by Watanabe and Yamada (1983).

The papillar area of the cheek, appearing to be rather large, is where corpuscles are found in the dense connective tissue.

Upon comparing the lamellae of lamellar cells in these corpuscles with those in 


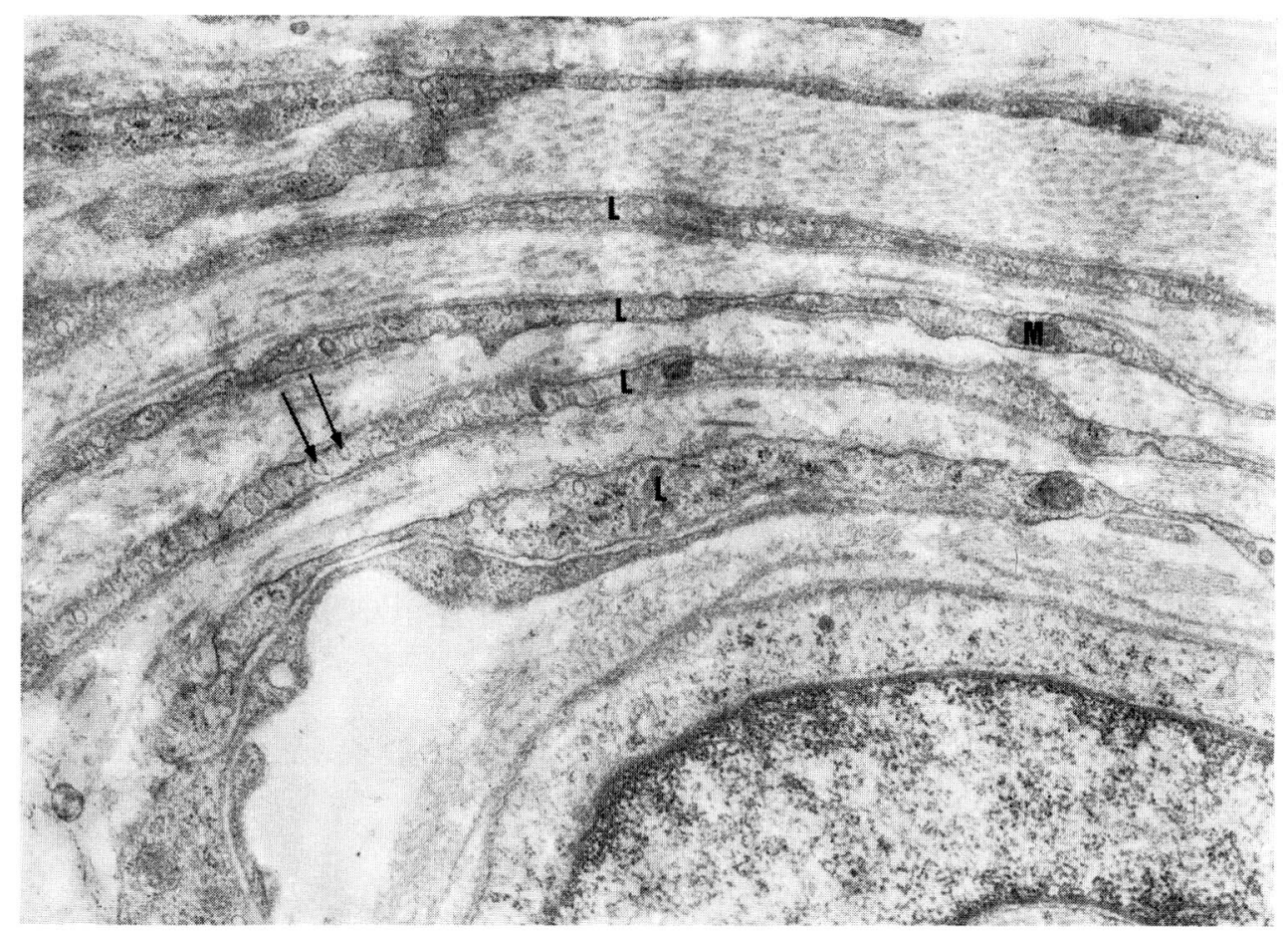

Fig. 5. Observe the capsulae of the lamellated corpuscle formed by several lamina $(L)$ of cytoplasmic extensions of perineural cells. The extensions show caveolae (arrows) and mitochondria ( $M$ ). $\times 56,000$

corpuscles described by Cauna and Ross (1960), Ide (1976, 1977), Ide and Munger (1978) and Halata and Munger (1983), we note that they are very similar in many aspects: the axon terminal has a large accumulation of mitochondria, clear vesicles and multivesicular bodies and are very similar to those described by PEASE and Quillian (1957). Quillian and Armstrong (1963), Andres (1966, 1969), Spencer and Schaumburg (1973), Andres and During (1973), Martinez and Pekarthy (1974), Munger (1975), Halata and Munger (1980), Spassova (1981), and Watanabe and Yamada (1983). All the corpuscles examined in the present study contained only one central axon terminal. Small cytoplasmic protrusions of the axon terminal extended into the lateral spaces. These extensions were characterized by containing many vesicles. They seem to have an intimate relationship with the mechanoreceptive functions of the corpuscle.

\section{REFERENCES}

Andres, K. H.: Über die Feinstruktur der Reseptoren an Sinushaaren. Z. Zellforsch. 75: 339-365 (1966).

-: Zur Ultrastruktur verschiedener Mechanorezeptoren von hoheren Wirbeltieren. Anat. Anz. 124: 551-565 (1969).

Andres, K. H. and M. von During: Morphology of cutaneous receptors: In: (ed. by) A. Iggo: Handbook of sensory physiology, Vol. II. Development of sensory systems. Springer-Verlag, Berlin, 1973 (Chap. 1, p. 3-28). 
Berkovitz, B. K. B., R. C. Chore and B. J. Moxham: The occurence of a lamellated nerve terminal in the periodontal ligament of the rat incisor. Arch. oral Biol. 28: 99-101 (1983).

Cauna, N. and L. L. Ross: The fine structure of Meissner's touch corpuscles of huma fingers. J. biophys. biochem. Cytol. 8: 467-482 (1960).

Chouchkov, H. N.: Ultrastructure of Pacinian corpuscles in men and cats. Z. mikrosk. anat. Forsch. 83: 17-32 (1971).

Garant, P. R., J. Feldman, M. I. Cho and M. R. Cullen: Ultrastructure of Merkel cells in hard palate of the squirrel monkey. Amer. J. Anat. 157: 155-167 (1980).

Halata, Z. and B. L. Munger: The ultrastructure of Ruffini and Herbst corpuscles in the articular capsule of domestic pigeon. Anat. Rec. 198: 681-692 (1980).

- : The sensory innervation of primate facial skin. II. Vermillion border and mucosa of lip. Brain Rev. 5: 81-107 (1983).

Hashimoto, K.: Fine structure of Merkel cell in human oral mucosa. J. Invest. Dermatol. 58: 381387 (1972).

Ide, C.: The fine structure of the digital corpuscle of the mouse toe pad, with special reference to nerve fibers. Amer. J. Anat. 147: 329-356 (1976).

- : Development of Meissner corpuscle of toe pad. Anat. Rec. 188: 49-68 (1977).

Ide, C. and B. L. Munger: A cytologic study of Grandy corpuscle development in chicken toe skin. J. comp. Neurol. 179: 301-324 (1978).

Martinez, B., Jr. and J. M. Pekarthy : Ultrastructure of encapsulated nerve endings in rat gingiva. Amer. J. Anat. 140: 135-138 (1974).

Munger, B. L.: Cytology of mechanoreceptors in oral mucosa and facial skin of the thesus monkey. In: (ed. by) D. B. Tower: The nervous system. Vol. 1. The basic neuroscience. R. O. Brady, Raven, New York, 19L5. (p. 71-79).

Munger, B. L and. L. M. Pubols : The sensorineural organization of the digital skin of the raccoon. Brain Behav. Evol. 5: 199-210 (1972).

Nikai, H., G. G. Rose and M. Cattoni : Merkel cell in human and rat gingiva. Arch. oral Biol. 16: 835-843 (1971).

Pease, D. C. and T. A. Quilliam: Electron microscopy of the paciniancorpuscle. J. biophys. biochem. Cytol. 3: 331-342 (1957).

Quilliam, T. A. and J. Armstrong : Mechanoreceptors. Endeavour 22: 55-60 (1963).

Saxod, R.: Ultrastructure of Merkel corpuscles and so-called transitional cells in the white leghorn chicken. Amer. J. Anat. 151: 453-474 (1978).

Spassova, I. : Ultrastructural relationship between the receptors nerve fiber and surrouding lamellae in Krause end-bulbs. Acta. anat. 109: 360-368 (1981).

Spencer, P. S. and. H. H. Schaumburg: An ultrastructural study of the inner core of the Pacinian corpuscle. J. Neurocytol. 2: 217-235 (1973).

Tachibana, T.: The Merkel cell in the labial ridge epidermis of anuran tadpole. I. Fine structure, distribution and cytochemical studies. Anat. Rec. 191: 487-502 (1978).

Tachibana, T., Y. Sakakura, K. Ishizeki, S. lida and T. Nawa: Migration of Merkel cells in the labial muco us epithelium of adult rabbits following mental nerve resection. Cell Tiss. Res. 223: 659-664 (1982).

Watanabe, I. and E. Yamada : The fine structure of lamellated corpuscles found in the rat gingiva. Acta. anat. nippon. 54: 300 (1979).

: The fine structure of lamellated nerve endings found in the rat gingiva. Arch. histol. jap. 46: 173-182 (1983).

Prof. Ii-Sei Watanabe

Department of Anatomy

Institut of Biomedical Science

University of São Paulo

São Paulo-Brasil 